\title{
Influence of light conditions on the morphogenetic and biochemical response of selected ornamental plant species under in vitro conditions: a mini-review
}

\author{
DARIUSZ KuluS *, ANITA WoźNY \\ Laboratory of Ornamental Plants and Vegetable Crops, Faculty of Agriculture and Biotechnology, \\ UTP University of Science and Technology in Bydgoszcz, Bydgoszcz, Poland
}

\begin{abstract}
In vitro tissue culture technique, especially micropropagation, is attracting increasing attention in the production of ornamental plants. This technique will probably dominate the horticultural market in the near future. Light is one of the several factors affecting the success of in vitro plant tissue cultures. It directly affects the widely understood morphogenetic response of the explant, i.e., the ability of the explant to grow or regenerate, produce roots, etc. Lighting conditions provided during the in vitro stage may also greatly affect the plant vigor after transferring to nonsterile conditions. Moreover, the necessity of providing artificial light significantly contributes to the total cost of maintaining tissue cultures (related to energy consumption and the need to cool down the heat generated by lamps). Light quantity (intensity) and quality (spectral composition) are the two main parameters that determine its influence on in vitro cultures. This impact depends on the species and other accompanying factors. The aim of this mini-review is to summarize information on the influence of light on the morphogenetic and biochemical response of explants of some selected ornamental plant species grown under in vitro conditions.

Key words: horticulture, LED panels, plant tissue culture, regeneration, secondary metabolites, somatic embryogenesis
\end{abstract}

\section{Introduction - the importance of tissue cultures in horticulture}

Tissue culture technology is a powerful tool applied in various areas of horticulture. It is successfully used in breeding (mutagenesis, transgenesis, protoplast fusion, haploid production, embryo rescue, and chimera separation) to obtain qualified, high-quality plant material (cryotherapy, meristem isolation) as well as in the protection of genetic resources (gene banks, artificial seeds, cryopreservation). In vitro cultures are also highly important to the pharmaceutical industry, as an acquisition method of valuable bioactive secondary metabolites of plant origin, for example, sclerotin, berberine, vincristine, vinblastine, etc. The most intensively exploited use of tissue culture is micropropagation, i.e., technology based on a large-scale reproduction of plants from a small tissue fragment - the so-called explant (Kulus, 2015a). By using this approach, it is possible to produce in a short time a large number of healthy plants on a small area regardless of climatic factors. Among the known micropropagation techniques, somatic embryogenesis seems to be the most efficient one (Kereša et al., 2012; Viehmannova et al., 2014).

Despite the obvious advantages, the use of tissue culture on the production scale is limited mainly to ornamental plants. This is because of the high cost associated with maintaining laboratories that are not yet competitive with the traditional method of vegetable, herb, or cereal plant propagation by seeds. Moreover, some species (e.g., woody plants) are considered "difficult" to regenerate in vitro (Kulus, 2015a). These problems can be resolved by appropriate optimization of tissue culture conditions, for example, light.

To date, several studies have investigated the impact of light conditions on the effectiveness of plant tissue culture. They date back to the 1950s and focus mainly

\footnotetext{
* Corresponding author: Laboratory of Ornamental Plants and Vegetable Crops, Faculty of Agriculture and Biotechnology, UTP University of Science and Technology in Bydgoszcz, Bernardyńska 6, PL-85-029 Bydgoszcz, Poland; email: dkulus@gmail.com
} 
on usable crops (Rappaport, 1954; Capite, 1955). The present study aimed to summarize the knowledge on the impact of light conditions on the morphogenetic and biochemical response of selected ornamental plant species cultured in vitro.

\section{Role of light in in vitro culture}

Factors determining the success of an in vitroculture system can be divided into two main groups: chemical and physical. Chemical factors include the type and concentration of growth regulators added to the medium, vitamins, antioxidants, solidifying and osmotically active substances, $\mathrm{pH}$, etc. Physical factors include mainly thermal and light conditions in the growth room or phytotron. Although plants grown in vitro are usually heteroor mixotrophic and their photosynthetic activity is limited (the source of carbon is supplied in the form of sugar in the synthetic medium), light still plays a key role in gene activity, primary and secondary metabolism, and the growth and development of explants - the so-called photomorphogenesis (Lin et al., 2011). This refers especially to the increasingly popular autotrophic culture system, i.e., in vitro culture kept under increased light intensity and with a low or no sugar content in the medium. Microshoots sense light through a system of photoreceptors, namely cryptochromes and phytochromes. If the intensity of light is too low, then symptoms of etiolation can be found, manifested by a lack of chlorophyll, deformation of leaves, and elongation and hyperhydration of shoots (Fig. 1). On the other hand, too much light can lead to the release of harmful reactive oxygen species (ROS) (Solymosi and Schoefs, 2010). Hence, both the quantity (intensity) and quality of light (spectrum composition) require careful optimization.

Red light and blue light are most important for plants grown in both in vivo and in vitro conditions (Lin et al., 2013). Blue light is involved in the biosynthesis of enzymes and chlorophyll (the light affects the total chlorophyll content and the ratio of chlorophyll $a$ and $b$, chloroplast development, and opening of stomata (Kim et al., 2004; Lin et al., 2011). Moreover, it elicits the plant defense response against stress associated with ROS activity (Mengxi et al., 2011). On the other hand, red light is important for shoot elongation, anatomical changes, and phytochrome activity (Shin et al., 2008). One should keep in mind, however, that in too high or
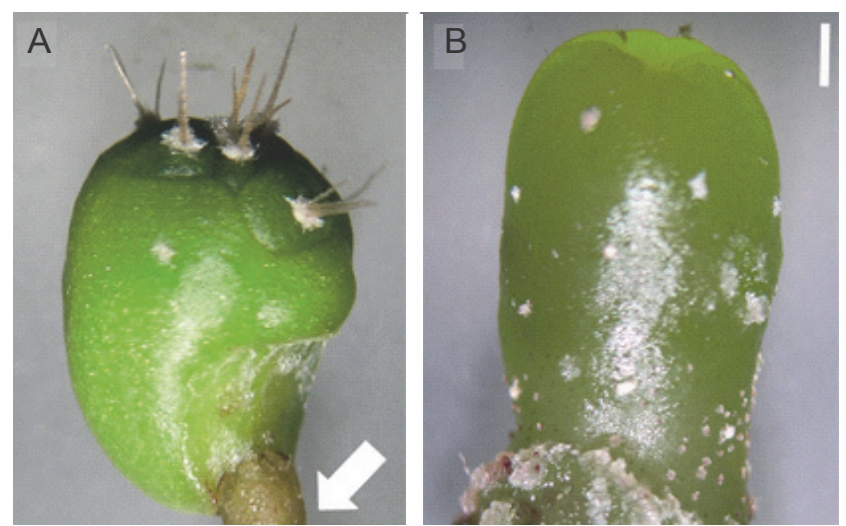

Fig. 1. Influence of light conditions on the development of microshoots of Astrophytum asterias cacti after 10 weeks of culture. A) typical microshoot with spines and a root (indicated with an arrow) produced under 16/8-h light/dark photoperiod; B) hyperhydrated spineless shoot of glossy appearance produced from a seedling explant incubated in the dark; bar $=1 \mathrm{~mm}$

too low quantities or in interaction with other factors, these wavelengths may also cause an unfavorable distribution of light energy available for photosystems I and II, resulting in the inhibition of plant growth.

Unlike humans, plants are least sensitive to green and yellow light. For example, microshoots of Plectranthus scutellarioides grown under green light (530 nm at peak) yielded significantly lower root and shoot dry mass than under other light treatments (Cho et al., 2019). This phenomenon is used in gene banks, in which to reduce the number of subcultures needed and to extend the life span of in vitro culture, plantlets are grown in light with a wavelength of 480 to $590 \mathrm{~nm}$ (Kulus, 2015b).

Daylight, on the other hand, is a combination of several light colors that cannot be distinguished by humans. However, in vitro culture cannot be kept in natural lighting as it is labile and changes during the day. Providing plants with artificial light is necessary to maintain the repeatability of test results as well as to standardize the production and make it independent of climatic and weather conditions.

\section{Light sources in in vitro culture}

The spectral composition and intensity of artificial light should provide the plant with proper developmental conditions. In the past, high-pressure sodium lamps (HPS), incandescent lamps, and metal-halide lamps were used in controlled cultivation (Gupta and Jatothu, 2013). 
Despite the high proportion of photosynthetically active radiation (PAR, PhAR) emitted (up to 40\%), they are no longer recommended for use due to the high radiant heat output; a high proportion of wavelengths with low significance for plant development; disturbed proportion of ultraviolet, red and far-red light; and a low share of blue light emitted (Ouzounisi et al., 2015).

In the last decade of the $20^{\text {th }}$ century and at the beginning of the $21^{\text {st }}$ century, it was recommended to use fluorescent lamps (FL) emitting white light, with a quantum radiation intensity in the range of $12-40 \mu \mathrm{mol} \cdot \mathrm{m}^{-2} \cdot \mathrm{s}^{-1}$, during a 16/8-h day/night photoperiod (Jerzy and Krzymińska, 2011). Traditional lighting systems based on FLs, however, have limited possibilities to control and adjust the intensity and composition of the optical spectrum (Bantis et al., 2016). Moreover, these parameters are not stable and change during the use of FLs (Darko et al., 2014). Another drawback is the uneven distribution of light on the shelf, which hinders research on the role of light in plant development. Fluorescent tubes also generate significant cost associated with the consumption of electricity and then removal of heat emitted by them; i.e., maintaining tissue culture is possible only when using air conditioners, which in turn can be a source of fungal spores. Expenditure on electricity is one of the highest and can constitute from $20 \%$ to even $60 \%$ of the total costs of a laboratory plant production, depending on the country and local climate (Tomar et al., 2007; Kulus, 2015a). From this pool, lighting consumes the most funds (approximately 85\%). FLs also have a limited efficiency. Although they provide plants with light in a broad wavelength range (350-750 nm), they emit little photosynthetically active radiation (PAR $=20-30 \%)$ due to the shortage of red light and far-red light (Miler et al., 2019). Hence, it is currently recommended to use light-emitting diodes (LEDs).

Application of LEDs not only reduces production costs (as LEDs require less energy and do not need cooling) but also helps to improve the quality of produced plants, i.e., increase dry matter and starch content in the cell. This quantitative and qualitative improvement is associated with the increased activity of the photosynthetic apparatus, resulting from the high proportion of red light (Xu et al., 2009). A high PAR content in LED light, reaching up to $80-100 \%$, is another advantage of the modules. The introduction of mixed LED modules (emitting red and blue or white light) has pro- ved to be the key in optimizing the spectrum for micropropagation of ornamental plants. This approach provides the possibility of precise mono- and polychromatic spectra testing. Additional advantages of diodes include their small surface $\left(2-5 \mathrm{~cm}^{2}\right)$ and longer life span (25000-100 000 h) compared with FLs (10000-15000 h) (Bantis et al., 2016). The long life span of this light source results in lower replacement cost (Woźny, 2015). Rapid development of LED technology in the recent years has contributed to the reduction of its price. This trend will most likely continue in the near future.

The use of diodes in in vitro culture as an alternative to traditionally used FL tubes has been reported in several studies conducted for the past 20 years (Tanaka et al., 1998; Lin et al., 2011; Azmi et al., 2016). The obtained results were promising in terms of plant development and proliferation rate. LEDs can also be applied during acclimatization of microshoots to ex vitro conditions (sometimes even combined with simultaneous rooting) - Figure 2, as reported in Chrysanthemum x grandiflorum (Woźny and Miler, 2016).

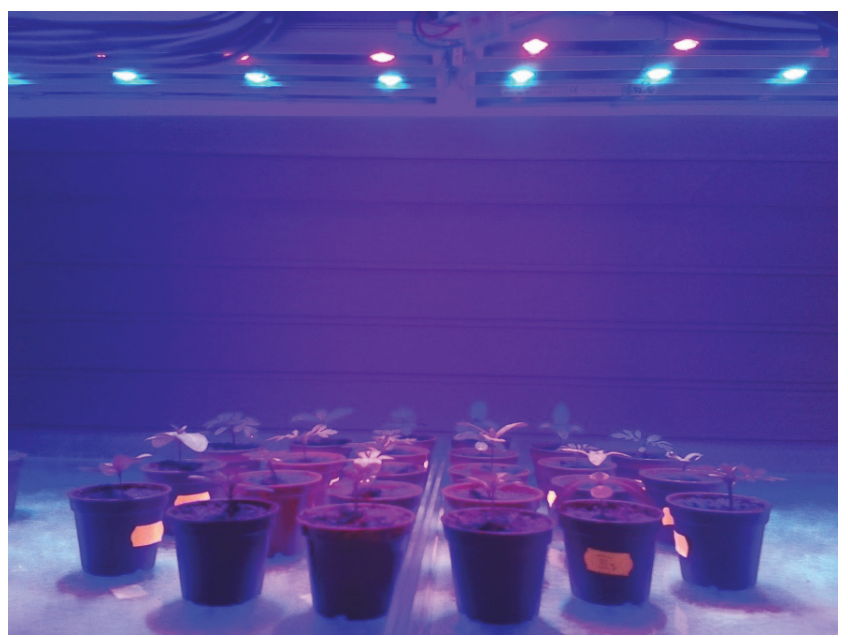

Fig. 2. Acclimatization of zinnia and marigold microshoots to $e x$ vitro conditions under LEDs

The current limitations of LED technology include the fact that the crystals used in their production cannot emit certain ranges of wavelengths with the power necessary for plant growth, for example, yellow or purple light (Growlux, personal communication). Another issue is the still high unit cost of the luminaire compared with FLs. Moreover, unlike traditional lighting systems, it is impossible to replace a single element in the LED panel. 
Consequently, in case of a malfunction, it is necessary to replace the entire luminaire (Gupta and Jatothu, 2013).

\section{Influence of light conditions on morphogenesis and regeneration of plants in vitro}

The influence of light is evident already at the stage of tissue culture initiation and during further morphogenetic response of explants, i.e., during growth and/or regeneration. This is because this factor affects the content of endogenous growth regulators, especially cytokinins and gibberellins (Manivannan et al., 2017). To date, most of the published studies focused on the impact of red and blue light (as well as their combination, usually in a $1: 1$ ratio) on the development of ornamental plants in in vitro culture (Werbrouck et al., 2012; Azmi et al., 2014; 2016).

\section{Aseptic seed sowing and in vitro culture initiation}

Light conditions play a vital role during in vitro culture initiation from seeds. For example, for some members of the Cactaceae family, aseptic seed sowing and germination are most effective in red light (Lema-Rumińska and Kulus, 2014). However, in Bletilla ochracea, seeds in asymbiotic conditions germinated most effectively in orange and green light (74\% germination ratio). Darkness, on the other hand, inhibited this process. Light conditions also influenced the further development of seedlings. Those kept in white or blue light had better vigor than seedlings kept in red, orange, and green light (Godo et al., 2011). Regarding axenic sowing of Phalenopsis orchid, the best results were found using the following light combination: $80 \%$ red and $20 \%$ blue. Further mericloning (proliferation of protocorm-like bodies; PLBs) was most effective when the proportion of red light and blue light was $90 \%$ and $10 \%$, respectively (Wongknok et al., 2008 ).

Light requirements of individual plant species grown in vitro are related to their natural habitat. For tropical plant species, popular in the floristic market, high photosynthetic photon flux density (PPFD) is recommended. Succulents are a good example. In 1999, Gratton and Fay, and then in 2003, Moebius-Goldammer et al. confirmed the positive effect of high light intensities (reaching up to $50 \mu \mathrm{mol} \cdot \mathrm{m}^{-2} \cdot \mathrm{s}^{-1}$ ) on the effectiveness of tissue culture in cacti. Similarly, in Spathiphyllum, a greater fresh mass of roots and shoots was found in microshoots grown under blue and red LEDs at
$60-75 \mu \mathrm{mol} \cdot \mathrm{m}^{-2} \cdot \mathrm{s}^{-1} \mathrm{PPFD}$ compared with that grown at $40 \mu \mathrm{mol} \cdot \mathrm{m}^{-2} \cdot \mathrm{s}^{-1}$ (Nhut et al., 2005). This approach also facilitates further acclimatization, as usually light intensity in the glasshouse is much higher than that in the growth room (up to $100 \mu \mathrm{mol} \cdot \mathrm{m}^{-2} \cdot \mathrm{s}^{-1}$ ). One should keep in mind, though, that at too high light intensity, tissue deformation, burns, and necrosis may also occur. This is due to the formation of water droplets on the plant surface causing the lens effect-air humidity in the culture vessel is very high, reaching even $100 \%$ (Kurilcik et al., 2008).

\section{Somatic embryogenesis}

In many ornamental plant species, darkness promotes the formation of somatic embryos because it delays the degradation of both phytohormones and exogenous growth regulators (Zeynali et al., 2010). This is important with auxins, which are particularly photolabile (Soontornchainaksaeng et al., 2001). Moreover, in the dark, cell wall thickness as well as cellulose and hemicellulose contents are reduced, which facilitates the transport of growth regulators (Zeynali et al. 2010). Conversion of embryos into plantlets, on the other hand, often requires their transfer to light (Kulus 2013). Ultimately, however, the optimal conditions depend on the species, variety/cultivar, and sometimes even genotype. In the cactus Astrophytum asterias, culturing seedling fragments at a 16-h photoperiod resulted in a significantly higher efficiency of somatic embryogenesis than that obtained with incubation in the dark; regarding the fresh weight of embryogenic callus, the share of regenerating explants, and the number of produced embryos (Kulus and Lema-Rumińska, 2016 ). Somatic embryos produced in light also had better vigor than nongreen embryos regenerated in the dark. Similar results were observed for adventitious shoot regeneration in A. asterias (Lema-Rumińska and Kulus, 2012) and Stenocereus gummosus (Shiskova et al., 2007). On the other hand, Gomes et al. (2006) developed an efficient protocol for regenerating Opuntia ficus-indica somatic embryos in the dark.

Regenerating in vitro embryogenic structures may be also sensitive to individual spectral ranges. For example, in the study by Lema-Rumińska and Fijałkowska (2006) on the regeneration of embryogenic callus in Gymnocalycium mihanovichii, somatic embryos were produced most often in yellow light $(70.8 \%$ explants), daylight 
(62.5\%), and red light (50\%). Darkness, blue, green, and white light were less effective (20.8-29.2\% embryogenesis efficiency).

\section{Organogenesis in vitro}

In the Oncidium orchid, red light stimulated the most intensive regeneration of PLBs and further elongation of shoots (Xu et al., 2009). For Cymbidium microshoots, red light stimulated callus proliferation and shoot differentiation, as well as leaf development (while reducing chlorophyll content). Blue light had an opposite effect (Tanaka et al., 1998). Similarly, in the in vitro cultures of Ficus benjamina, red light caused the most intense regeneration of shoots; however, light color did not affect the rooting of microshoots (Gabryszewska and Rudnicki, 1997). In contrast, in Rosa kordesii, blue light stimulated the development of the highest number of shoots and leaves in vitro (Azmi et al., 2016). In two cultivars of Dianthus caryophyllus, blue light favored the activation of axillary buds (Manivannan et al., 2017). Blue light also positively affected the elongation of Zantedeschia jucunda 'Black Magic' microshoots, although the highest dry weight was found in plants kept under fluorescent lamps (Jao et al., 2005). On the other hand, in Rehmannia glutinosa, the highest dry mass of microshoots was reported after using blue light, while twice as long shoots were obtained in red light (Hahn et al., 2000). For Cattleya orchid hybrid, the propagation coefficient depended on light color and reached 11.7 for red light, 10.6 for blue light, 8.3 for white light, and 6.2 in darkness (Cybularz-Urban et al., 2007). By using optimal lighting conditions, the authors managed to accelerate the regeneration of this naturally slow-growing hybrid. This is especially significant for endangered plant species, often found among ornamentals.

It is generally assumed that red light stimulates shoot elongation, while blue inhibits this process. However, the final effect is species- or even cultivar-dependent. For example, microshoots of Dianthus caryophyllus 'Green Beauty' produced longer shoots in red light, while this effect was not observed with 'Purple Beauty' (Manivannan et al., 2017). The varied effect of light on the course of morphogenesis in vitro may be associated with the influence of this factor on the content and activity of endogenous growth regulators. Therefore, the use of more than one light color/range in the subsequent stages of in vitro propagation seems to be a good solution.
Lian et al. (2002) determined the effect of various light spectra (red, blue, mixed red and blue, fluorescent, and dark) on the regeneration of adventitious bulbs from bulb scales in Lilium 'Pesaro'. Regeneration occurred in all experimental combinations, with the highest proportion of regenerating explants and multiplication ratio found in mixed and fluorescent light. Moreover, the use of mixed LED light allowed to produce bulbs of the greatest size, dry and fresh weight, and number of roots. For Chrysanthemum $\times$ grandiflorum, a positive effect of mixed light on the fresh and dry weight of microshoots, leaf surface, and chlorophyll content was reported. Blue light alone had an inhibitory effect on the development of microshoots and their rooting. On the other hand, red light stimulated the most intensive growth of shoots by internode elongation (the number of nodes did not change), which resulted in the poor quality of shoots (Kim et al., 2004). The use of mixed light also contributed to a higher multiplication ratio in Vanilla planifolia (Bello-Bello et al., 2016), Rosa kordesii (Azmi et al., 2014), and Anthurium andreanum cultures (MartinezEstrada et al., 2016). The beneficial effect of mixed light (red and blue) on the growth and development of microshoots results from its positive effect on the photosynthesis intensity - energy distribution of red and blue spectrum coincides with the chlorophyll and phytochrome absorption maxima (Kim et al., 2004). Most of the available literature studied the use of red and blue light in a $1: 1$ ratio. However, other combinations should also be analyzed and evaluated. For example, Kurilcik et al. (2008) found that the optimal spectrum composition for Chrysanthemum $\times$ grandiflorum micropropagation is $14 \%$ blue light $(450 \mathrm{~nm}), 50 \%$ red $(640 \mathrm{~nm}), 28 \%$ red $(660 \mathrm{~nm})$, and $8 \%$ far-red light $(675 \mathrm{~nm})$ at $40 \mu \mathrm{mol} \cdot \mathrm{m}^{-2} \cdot \mathrm{s}^{-1}$ and a $16-\mathrm{h}$ photoperiod. In Anthurium, on the other hand, more intensive root regeneration was achieved with an increased proportion of red light in relation to blue light (Budiarto 2010). The combination of red and green light increased more than twice as much roots and dry mass in Plectranthus scutellarioides as compared to that by white light. Moreover, the combination of red and green light led to morphological changes, including larger leaves and longer petioles and internodes than those in other light treatments (Cho et al., 2019).

Dewir et al. (2006) analyzed the effect of light color on the in vitro flowering of photoperiodically neutral 
Euphorbia milii. They found that the combinations of blue alone, red with far-red, and blue with far-red stimulated flowering, while red light alone suppressed this process. The highest proportion of flowering plants $(90 \%)$, with the highest number of inflorescences, produced in the shortest time, was found under fluorescent lamps. These results confirm the possibility of conducting synchronized laboratory production of flowering ornamentals.

It should be highlighted that the impact of light on the development of tissue culture may also depend on other factors. For example, the effect of light color on the intensity of photosynthesis in Rehmannia glutinosa depended on the sugar content in the medium and on the intensity of culture ventilation (Hahn et al., 2000). For Chrysanthemum $\times$ grandiflorum, the final effect of light conditions varied depending on the developmental phase of microshoots (Kurilcik et al., 2008). A significant interaction was also observed between light intensity and concentration of N-benzyladenine in the culture medium on the shoot proliferation and development, leaf architecture, and content of photosynthetic pigments in Gerbera jamesonii and Myrtus communis cultured in vitro (Cioć et al., 2018, Cioć et al., 2019).

The results described here suggest that for the full optimization of production, individual stages of micropropagation, i.e., culture initiation, multiplication, rooting, and hardening, require different lighting conditions, even within the same species. For example, in the Doritaenopsis orchid, red light stimulated the most intense leaf development while inhibiting rooting. The opposite effect was observed using blue light (Shin et al., 2008). For Anthurium andreanum, more intensive callus regeneration from leaf explants was found with an increased share of red light, while blue light more effectively stimulated the regeneration of adventitious shoots $(\mathrm{Bu}-$ diarto, 2010). This is worth considering when developing micropropagation procedures on a commercial scale and when designing high-scale production laboratories.

\section{Hardening and acclimatization}

Hardening and acclimatization are critical stages in laboratory plant production. This is because microshoots derived from in vitro conditions have a poorly developed cuticle and dysfunctional stomata (resulting in transpiration disorders), making them sensitive to heat and high solar radiation. Hence, they must be properly adapted to ex vitro conditions. The use of non-heating LEDs can be very helpful during this stage.

In the study with Spathiphyllum, microshoots grown under LEDs emitting a spectrum of $80 \%$ red and $20 \%$ blue light showed better ex vitro growth than plants grown under FLs (Nhut et al., 2005). This highlights the legitimacy of using diodes.

\section{Influence of light conditions on the biosynthesis of secondary metabolites}

Light also affects the biochemical activity of cells. Many metabolites are synthesized in plastids (terpenoids) or depend on light for their activity (phenylpropanoids). However, this influence is species-specific. For example, in the orchid Anoectochilus formosanus, the increase in light intensity (from 10 to $90 \mu \mathrm{mol} \cdot \mathrm{m}^{-2} \cdot \mathrm{s}^{-1}$ ) resulted in the increase in superoxide dismutase (SOD) activity, and consequently, in the enhancement of flavonoid biosynthesis, while reducing the content of chlorophyll (Ma et al., 2010). Similarly, stress associated with photoinhibition stimulates the accumulation of secondary metabolites and flavonoid pigments in Melastoma malabathricum cells. The enhanced production of flavonoids (mainly anthocyanins) can be explained by the defense reaction of the plant, as it tries to limit the action of photo-activated oxygen free radicals (Lee and Gould, 2002). On the other hand, in Orthosiphon stamineus, an increase in light intensity led to a decrease in the content of secondary metabolites, namely flavonoids and polyphenols (Ibrahim and Jaafar, 2012).

In addition to light intensity, its quality is important for the biochemical activity of plant cells (Pawłowska et al., 2018). The content and composition of essential oils in the leaves of Lippia alba are affected by the genotype and quality of light used during micropropagation (Batista et al., 2016). In Petunia $\times$ hybrida 'Mitchell Diploid', red light and far-red stimulated the production of the volatile 2-phenylethanol compound (Colquhoun et al., 2013). On the other hand, in the Doritaenopsis orchid, blue light (alone or in combination with red light) stimulated the accumulation of starch compared with microshoots grown in red and fluorescent light (Shin et al., 2008). For Oncidium in vitro culture, red light stimulated the accumulation of starch, while blue LEDs elevated the cellular enzymatic activity and pigment synthesis (Xu et al., 2009; Mengxi et al., 2011). These findings are va- 
luable for the pharmaceutical industry, as many ornamental plant species are a source of health-promoting secondary metabolites with anticancer, antiviral, antibacterial, and fungistatic effects.

\section{Conclusions}

The influence of light conditions on the in vitro development of explants is undeniable. Both the quantity and quality of light determine the embryogenic and regenerative potentials and the metabolic activity of plant cells. However, despite its key role, this factor is often neglected when optimizing in vitro culture conditions. This is probably because in the past, the effect of light color on plant growth and development was studied using colored membranes and FLs with a fluorescent filter. These methods, however, were inaccurate and unreliable. Currently, LEDs are used for this purpose, as they are the only tool that allows for the full control of lighting parameters.

The development of optoelectronics has led to the replacement of the so-far used fluorescent lamps with LEDs, which are a cheaper and more ecological solution. Moreover, microshoots produced under light conditions provided by LEDs are often of better quality, although the mechanism of these changes is not yet well understood. In the future, more attention should be focused on the interaction between light conditions and the level of endogenous phytohormones. Moreover, studies on the impact of other, less popular but also important, light wavelengths/colors on the development of plant tissue in vitro should be performed, both alone and in combination with the standard red and blue light.

\section{Reference}

Azmi N.S., Ahmad R., Ibrahim R. (2014) Effects of red and blue (RB) LED on the in vitro growth of Rosa kordesii in multiplication phase. $2^{\text {nd }}$ Int. Conf. Agric. Biotechnol. IPCBEE 79: 20-24.

Azmi N.S., Ahmad R., Ibrahim R. (2016) Fluorescent light $(F L)$, red led and blue led spectrums effects on in vitro shoots multiplication. J. Teknologi 78: 93-97.

Bantis F., Ouzounis T., Radoglou K. (2016) Artificial LED lighting enhances growth characteristics and total phenolic content of Ocimum basilicum, but variably affects transplant success. Sci. Hortic. 198(26): 277-283.

Batista D.S., de Castro K.M., da Silva A.R., Teixeira M.L., Sales T.A., Soares I.L., Cardoso M., das Gracas Santos M.O., Viccini L.F., Otoni W.C. (2016) Light quality affects in vitro growth and essential oil profile in Lippia alba (Verbenaceae). In Vitro Cell. Dev. Biol. Plant 52: 276-282.

Bello-Bello J.J., Martinez-Estrada E., Caamal-Velăzguez J.H., Morales-Ramos V. (2016) Effects of LED light quality on in vitro shoot proliferation and growth of vanilla (Vanilla planifolia Andrews). Afr. J. Biotechnol. 15(8): 272-277.

Budiarto K. (2010) Spectral quality affects morphogenesis on Anthurium plantlet during in vitro culture. Agrivita 32: 234-240.

Capite de L. (1955) Action of light and temperature on growth of plant tissue cultures in vitro. Am. J. Bot. 42(10): 869-873.

Cioć M., Kalisz A., Żupnik M., Pawłowska B. (2019) Different LED light intensities and 6-benzyladenine concentrations in relation to shoot development, leaf architecture, and photosynthetic pigments of Gerbera jamesonii Bolus in vitro. Agronomy 9: 358.

Cioć M., Szewczyk A., Żupnik M., Kalisz A., Pawłowska B. (2018) LED lighting affects plant growth, morphogenesis and phytochemical contents of Myrtus communis $L$. in vitro. Plant Cell Tiss. Organ. Cult. 132(3): 433-447.

Cho K.H., Laux V.Y., Wallace-Springer N., Clark D.G., Folta K., Colquhoun T.A. (2019) Effects of light quality on vegetative cutting and in vitro propagation of coleus (Plectranthus scutellarioides). HortSci. 54(5): 926-935.

Colquhoun T.A., Schwieterman M.L., Gilbert J.L., Jaworki E.A., Langer K.M., Jones C.R., Rushing G.V., Hunter T.M., Olmstead J., Clark D.G., Folta K.M. (2013) Light modulation of volatile organic compounds from petunia flowers and select fruits. Postharv. Biol. Technol. 86: 37-44.

Cybularz-Urban T., Hanus-Frajerska E., Świderski A. (2007) Effect of light wavelength on in vitro organogenesis of a Cattleya hybrid. Acta Biol. Cracov. Bot. 49(1): 113-118.

Darko E., Heydarizadeh P., Schoefs B., Sabzalian M.R. (2014) Photosynthesis under artificial light: the shift in primary and secondary metabolism. Philos. Trans. R. Soc. Lond. B Biol. Sci. 369(1640): 20130243.

Dewir Y.H., Chakrabarty D., Hahn E.J., Paek K.Y. (2006) Flowering of Euphorbia millii plantlets in vitro as affected by paclobutrazol, light emitting diodes (LEDS). Acta Hortic. 764: 169-173.

Gabryszewska E., Rudnicki R.M. (1997) The effects of light quality on the growth and development of shoots and roots of Ficus benjamina in vitro. Acta Hortic. 418: 163-168.

Godo T., Fujiwara K., Guan K., Miyoshi K. (2011) Effect of wavelength of LED-light on in vitro asymbiotic germination and seedling growth of Bletilla ochracea schltr (Orchidaceae). Plant Biotechnol. 28: 397-400.

Gomes F.L.A.F., Heredia F.F., Silva P.B., Faco O., Paiva Campos de F.A. (2006) Somatic embryogenesis and plant regeneration in Opuntia ficus-indica (L.) Mill. (Cactaceae). Sci. Hortic. 108: 15-21.

Gratton J., Fay F.M. (1999) In vitro propagation of succulent plants. Meth. Molec. Biol. 111: 135-140.

Gupta S.D., Jatothu B. (2013) Fundamentals and applications of light-emitting diodes ( $L E D S$ s) in in vitro plant growth and morphogenesis. Plant Biotechnol. Rep. 7(3): 211-220. 
Hahn E.J., Kozai T., Paek K.Y. (2000) Blue and red lightemitting diodes with or without sucrose and ventilation affect in vitro growth of Rehmannia glutinosa plantlets. J. Plant Biol. 43: 247-250.

Ibrahim M.H., Jaafar H.Z. (2012) Primary, secondary metabolites, $\mathrm{H}_{2} \mathrm{O}_{2}$, malondialdehyde and photosynthetic responses of Orthosiphon stimaneus Benth. to different irradiance levels. Molec. 17(2): 1159-1176.

Jao R.C., Lai C.C., Fang W., Chang S.F. (2005) Effect of red light on the growth of Zantedeschia plantlets in vitro and tuber formation using light emitting diodes. Hort. Sci. 40(2): 436-438.

Jerzy M., Krzymińska A. (2011) Rozmnażanie roślin ozdobnych in vitro. [in:] Rozmnażanie wegetatywne roślin ozdobnych. PWRiL. Poznań: 5-7; 83-105.

Kereša S., Mihovilović A., Barić M., Židovec V., Skelin M. (2012) The micropropagation of chrysanthemums via axillary shoot proliferation and highly efficient plant regeneration by somatic embryogenesis. Afr. J. Biotechnol. 11(22): 6027-6033.

Kim S.J., Hahn E.J., Heo J.W., Paek K.Y. (2004) Effects of LEDs on net photosynthetic rate, growth and leaf stomata of Chrysanthemum plantlets in vitro. Sci. Hortic. 101: 143-151.

Kulus D. (2013) Embriogeneza somatyczna in vitro. [in:] Nowe Trendy w Naukach Przyrodniczych 4, v. IV. Ed. Kuczera M. CreativeTime. Kraków: 45-54.

Kulus D. (2015a) Selected aspects of ornamental plants micropropagation in Poland and worldwide. Life Sci. 4(10): 10-25.

Kulus D. (2015b) Zjawisko erozji genetycznej jako zagrożenie dla biobezpieczeństwa wspótczesnego świata. [in:] Bezpieczeństwo współczesnego świata: Historia, wyzwania, konflikty zbrojne. Ed. Karwat J. Maiuscula. Poznań: 215-225.

Kulus D., Lema-Rumińska J. (2016) Induction of embryogenic callus in Astrophytum asterias (Zucc.) Lem. in vitro cultures. [in:] Badania i rozwój młodych naukowców w Polsce - nauki przyrodnicze V. Ed. Panfil M. Młodzi Naukowcy. Poznań: 124-132.

Kurilcik A., Canova M.R., Dapkuniene S., Zilinskaite S., Kurilcik G., Tamulaitis G., Duchovskis, P., Zukauskas, A. (2008) In vitro culture of Chrysanthemum plantlets using light emitting diodes. Cent. Eur. J. Biol. 3: 161-167.

Lee D.W., Gould K.S. (2002) Why leaves turn red: pigments called anthocyanins probably protect leaves from light damage by direct shielding and by scavenging free radicals. Am. Sci. 90: 524-531.

Lema-Rumińska J., Fijałkowska A. (2006) Dynamika wzrostu kalusa oraz regeneracja struktur embrioidalnych u kaktusa z rodzaju Gymncalycium w zależności od warunków świet1nych. ZPPNR 510: 325-331.

Lema-Rumińska J., Kulus D. (2012) Induction of somatic embryogenesis in Astrophytum asterias (Zucc.) Lem. in the aspect of light conditions and auxin 2,4-D concentrations. Acta Sci. Pol., Hort. Cult. 11(4): 77-87.

Lema-Rumińska J., Kulus D. (2014) Micropropagation of cacti - a review. Haseltonia 19: 46-63.
Lian M.L., Murthy H.N., Paek K.Y. (2002) Effects of light emitting diodes ( $L E D)$ on the in vitro induction and growth of bulblets of Lilium oriental hybrid 'Pesaro'. Sci. Hortic. 94: 365-370.

Lin K.-H., Huang M.Y., Huang W.-D., Hsu M.-H., Yang Z.-W., Yang C.-M. (2013) The effects of red, blue, and white lightemitting diodes on the growth, development, and edible quality of hydroponically grown lettuce (Lactuca sativa $L$. var. capitata). Sci. Hortic. 150(4): 86-91.

Lin Y., Li J., Li B., He T., Chun Z. (2011) Effects of light quality on growth and development of protocorm - like bodies of Dendrobium officinale in vitro. Plant Cell. Tiss. Org. Cult. 105(3): 329-335.

Ma Z., Li S., Zhang M. (2010) Light intensity affects growth, photosynthetic capability, and total flavonoid accumulation of Anoectochilus plants. HortSci. 45(6): 863-867.

Manivannan A., Soundararajan P., Park Y.G., Wei H., Kim SH., Jeong B.R. (2017) Blue and red light-emitting diodes improve the growth and physiology of in vitro grown carnations 'Green Beauty' and 'Purple Beauty'. Hortic. Environ. Biotechnol. 58(1): 12-20.

Martinez-Estrada E., Caamal-Velăzguez J.H., Morales-Ramos V., Bello-Bello J.J. (2016) Light emitting diodes improve in vitro shoot multiplication and growth of Anthurium andreanum Lind. Prop. Orn. Plants 16(1): 3-8.

Mengxi L., Zhigang X., Yang Y., Yijie F. (2011) Effects of different spectral lights on Oncidium PLBs induction, proliferation and plant regeneration. Plant Cell. Tiss. Org. Cult. 106(1): 1-10.

Miler N., Kulus D., Woźny A., Rymarz D., Hajzer M., Wierzbowski K., Nelke R., Szeffs L. (2019) Application of widespectrum light-emitting diodes in micropropagation of popular ornamental plant species: a study on plant quality and cost reduction. In Vitro Cell. Develop. Biol. Plant. 55: 99.

Moebius-Goldammer K.G., Mata-Rosas M., Chavez-Avila V.M. (2003) Organogenesis and somatic embryogenesis in Ariocarpus kotschoubeyanus (Lem.) K. Schum. (Cactaceae), an endemic and endangered Mexican species. In Vitro Cell. Develop. Biol. Plant 39: 388-393.

Nhut D.T., Takamura T., Watanabe H., Okamoto K., Tanaka M. (2005) Artificial light source using light-emitting diodes (LEDs) in the efficient micropropagation of Spathiphyllum plantlets. Acta Hortic. 692: 137-142.

Ouzounis T., Rosenqvist E., Ottosen C.-O. (2015) Spectral effects of artificial light on plant physiology and secondary metabolism: a review. HortSci. 50(8): 1128-1135.

Pawłowska B., Żupnik M., Szewczyk-Taranek B., Cioć M. (2018) Impact of LED light sources on morphogenesis and levels of photosynthetic pigments in Gerbera jamesonii grown in vitro. Hortic. Environ. Biotechnol. 59(1): 115-123.

Rappaport J. (1954) In vitro culture of plant embryos and factors controlling their growth. Bot. Rev. 20: 201.

Shin S.K., Murthy N.H., Heo W.J., Hahn J.E., Paek Y.K. (2008) The effect of light quality on the growth and development 
of in vitro cultured Doritaenopsis plants. Acta Physiol. Plantae 30: 339-343.

Shiskova S., Garcia-Mendoza E., Castillo-Diaz V., Moreno N.E., Arellano J., Dubrovsky J.G. (2007) Regeneration of roots from callus reveals stability of the developmental program for determinate root growth in Sonoran Desert Cactaceae. Plant Cell Rep. 26: 547-557.

Solymosi K., Schoefs B. (2010) Etioplast and etio-chloroplast formation under natural conditions: the dark side of chlorophyll biosynthesis in angiosperms. Photosynth. Res. 105: 143-166.

Soontornchainaksaeng P., Chaicharoen S., Sirijuntarut M., Kruatrachue M. (2001) In vitro studies on the effect of light intensity on plant growth of Phaius tankervilliae (Banks ex L'Herit.) Bl. and Vanda coerulea Griff. Sci. Asia 27: 233-237.

Tanaka M., Takamura T., Watanabe H., Endo M., Panagi T., Okamoto K. (1998) In vitro growth of Cymbidium plantlets cultured under superbright red and blue light-emitting diodes. J. Hortic. Sci. Biotechnol. 73: 39-44.

Tomar U.K., Negi U., Sinha A.K., Kumar P. (2007) An overview on economic factors influencing micropropagation. My Forest 43: 523-534.

Viehmannova I., Bortlova Z., Vitamvas J., Cepkova P.H., Eliasova K., Svobodova E., Travnickova M. (2014) Assessment of somaclonal variation in somatic embryo-derived plants of yacon [Smallanthus sonchifolius (Poepp. and Endl.) $H$. Robinson] using inter simple sequence repeat analysis and flow cytometry. Electr. J. Forestry 17(2): 102-106.

Werbrouck S., Buyle H., Geelen D., Van Labeke M.C. (2012) Effect of red-far-red and blue-light-emitting diodes on in vitro growth of Ficus benjamina. Acta Hortic. 961: 533-538.

Wongnok A., Piluek C., Techasilpitak T., Tantivivat S. (2008) Effect of light emitting diodes on micropropagation of Phalaenopsis orchids. Acta Hortic. 788: 149-156.

Woźny A. (2015) Źródła światła wykorzystywane w produkcji ogrodniczej. Pr. Instyt. Elektrotechniki 62(269): 47-54.

Woźny A., Miler N. (2016) LEDs application in ex vitro rooting and acclimatization of chrysanthemum (Chrysanthemum $\times$ grandiflorum /Ramat./ Kitam.). Electron. J. Polish Agric. Univ. 19(4): 302.

Xu Z.G., Cui J., Jiao X.L. (2009) Effects of different spectral energy distribution on tissue culture of Oncidium in vitro. J. Beijing For. Univ. 31(4): 45-50.

Zeynali M., Maleki B., Amiri E., Noruzian M., Aghajari S. (2010) Influence of genotype and plant growth regulators on somatic embryogenesis in rapeseed (Brassica napus L.). Afr. J. Biotechnol. 9(26): 4050-4055. 